\title{
Autism Educators in Morgantown, W.Va. A Multimedia Story on Their Trials and Triumphs
}

\author{
Shishira Nanjangud Sreenivas
}

Follow this and additional works at: https://researchrepository.wvu.edu/etd

\section{Recommended Citation}

Nanjangud Sreenivas, Shishira, "Autism Educators in Morgantown, W.Va. A Multimedia Story on Their Trials and Triumphs" (2016). Graduate Theses, Dissertations, and Problem Reports. 6292.

https://researchrepository.wvu.edu/etd/6292

This Thesis is protected by copyright and/or related rights. It has been brought to you by the The Research Repository @ WVU with permission from the rights-holder(s). You are free to use this Thesis in any way that is permitted by the copyright and related rights legislation that applies to your use. For other uses you must obtain permission from the rights-holder(s) directly, unless additional rights are indicated by a Creative Commons license in the record and/ or on the work itself. This Thesis has been accepted for inclusion in WVU Graduate Theses, Dissertations, and Problem Reports collection by an authorized administrator of The Research Repository @ WVU. For more information, please contact researchrepository@mail.wvu.edu. 
Autism Educators in Morgantown, W.Va. A Multimedia Story on Their Trials and Triumphs

Shishira Nanjangud Sreenivas

A project submitted to The Reed College of Media at West Virginia University as a partial fulfillment of the requirements for the degree of

Master of Science in

Journalism

Dana Coester, M.A., Chair

Emily Corio, M.S.J.

Lois Raimondo, M.A.

Kimberly Floyd, Ph.D.

Morgantown, West Virginia

2016

Keywords: Autism Spectrum Disorder, ASD, Autism Educators, Audiovisual, Multimedia

Copyright 2016 Shishira Nanjangud Sreenivas 


\section{ABSTRACT \\ Autism Educators in Morgantown, W.Va. A Multimedia Story on Their Trials and Triumphs Shishira Nanjangud Sreenivas}

This professional project consists of an external website with four audiovisual multimedia projects. The projects are photos and audio sound bites of four educators who possess different areas of specialty in teaching and assisting children with autism. Each of the educators showcased in this project address the realities of teaching children with Autism Spectrum Disorder and reveal particular issues that affect autistic children seeking special education in Morgantown, West Virginia. Additionally, the project discusses social responsibility, previous media coverage on autism, and also examines where West Virginia stands social-economically compared to some its neighboring states. 


\section{ACKNOWLEDGEMENTS}

I would firstly like to thank the Reed College of Media's faculty and staff as well as my cohorts for their continual guidance and support through out my undergraduate and graduate schooling at West Virginia University. Each and every class has helped me develop a strong understanding of the journalistic ethics and standards that I will strive to live by throughout my professional career in journalism.

I would especially like to thank my committee members: Professor Dana Coester, Professor Emily Corio, Professor Lois Raimondo and Dr. Kimberly Floyd. Each of the members has served as a wonderful mentor, paying great attention to detail, and helping me with a good set of resources and guidelines to achieve this project to completion.

I would also like to thank my parents for their continued support and encouragement throughout my academic years. Their advise, moral support and love has always helped me pursue my goals diligently and with a strong sense of commitment.

Finally, I would like to thank the educators, parents and, most importantly, the children who welcomed me into their space to better understand their stories and document them with audio interviews and photographs. Thank you for letting me share your story. 


\section{TABLE OF CONTENTS}

ACKNOWLEDGEMENTS

iii

INTRODUCTION AND

BACKGROUND

Professional and Educational

Qualifications

\section{PROFESSIONAL PROJECT}

Project Description

Project Timeline

Project Dissemination

Intended Audience

Potential Publication Source

Research Statement

Methodology

Interview Questions

11

External Website

12

Survey

Survey Results

LITERATURE REVIEW

Previous Media Coverage on

Autism Spectrum Disorder

Effects of Multimedia Storytelling

Health and Science Reporting

Media Theories

Civic Journalism

Social Responsibility Theory 
CONCLUSION $\quad 23$

Limitations $\quad 23$

Future Research

SOURCES 26

APPENDICES $\quad 28$

1. Consent Form $\quad 29$

2. Survey $\quad 30$

3. Example of Adobe Audition Timeline $\quad 31$

4. Example of Soundslides

Timeline

5. External Website:

Autism Educators in

Morgantown, W.Va.

A Multimedia Story on their

Trials and Triumphs**

**External website is not

available in this document,

but can be found at

https://autisminmorgantown.

wordpress.com/

\section{LIST OF TABLES}

Table 1. IDEA Funding for FY 


\section{Introduction and Background}

Autism Spectrum Disorder (ASD) is a neurodevelopmental disorder that is characterized by limited social interactions and social communicating and also by restricted and repetitive behavior (National Autism Center, 2015). According to the Centers for Disease Control and Prevention (CDC), 1 in 68 children are diagnosed with ASD and it occurs in all racial, ethnic, and socioeconomic groups; and is 4.5 times more common in boys than in girls (CDC, 2015). With an annual growth rate of about 10 percent to 17 percent, autism is one of the fastest growing developmental disordes (Intensive Autism Service Delivery Clinic, 2016). In West Virginia alone, according to a 2009 CDC study, there were 16,000 people diagnosed with ASD and among them, about 3,500 were under the age of 18 (Charleston Gazette, 2012). Symptoms usually include: lack of eye contact during conversations, poor peer relations, delayed or lack of development of natural speech, repetitive patterns of behavior, language and interests and many more (National Education Association, 2002-2015). The diagnosis of ASD can be done as early as eighteen months but, by age two or older, a diagnosis by a medical professional is more reliable (Lord C, Risi S, DiLavore PS, Shulman C, Thurm A \& Pickles A, 2006).

According to the CDC, schools play a vital role in evaluating and serving children with ASD (2016). Due to the growing numbers of children on the spectrum requiring special attention, there has been a significant demand for special needs educators to cater to these children. Parents and families often turn to health professionals equipped to deal with the complexities a child faces with autism. A complex disability like autism isn't usually manageable when professionals from separate disciplines practice in isolation (Raffin, 2001). The current knowledge of autism is such that for immediate result and improvement in the quality of life for autistic kids and their families, it requires a multidisciplinary approach that 
includes a combination of special education, therapy and medical interventions are required during the early stages and throughout the child's life (Raffin, 2001). These professionals could be behavioral psychologists, doctors, speech-language pathologists, occupational therapists, physical therapists and more. According to research conducted by the CDC, their acts of early intervention have a large impact on the future for a child with ASD.

According to the National Research Council (2001) recommendations, children with autism require twenty-five hours of intensive instruction every week including daily activities that aid their learning. However, West Virginia suffers from lack of resources in terms of certified autism educators and the financial resources necessary to help all those in need.

The Individuals with Disabilities Education Act (IDEA) passed in 2004 assumes that the cost of educating children with special needs costs at least twice the amount necessary for other children (National Education Association, 2016). Congress had determined to pay up to $40 \%$ of the costs associated with excess financial burden faced by families with children with disabilities. However, since 2009, the federal share received per child has stagnated to less than half of the appropriation along with the number of students it's able to serve.

According to the National Education Association (2016), in fiscal year 2015, the average federal share per child with disabilities was $\$ 1,742$. A $\$ 1$ rise as compared to the amount is fiscal year 2009 at $\$ 1,741$. In fiscal year 2015, West Virginia received significantly lesser in federal appropriation as compared to its neighboring states (see table 1). However, the comparison table does not show the approximate population in each state reliant on special needs funds. 


\begin{tabular}{|l|r|r|}
\hline \multicolumn{1}{|c|}{ State } & \multicolumn{1}{c|}{$\begin{array}{c}\text { Appropriation } \\
\text { (in millions) }\end{array}$} & $\begin{array}{c}\text { Full Funding } \\
\text { (in millions) }\end{array}$ \\
\hline Maryland & $\$ 197.8$ & $\$ 494.1$ \\
\hline Ohio & $\$ 431.5$ & $\$ 1,077.9$ \\
\hline Pennsylvania & $\$ 421.2$ & $\$ 1,052.1$ \\
\hline Virginia & $\$ 281.0$ & $\$ 701.8$ \\
\hline West Virginia & $\$ 75.1$ & $\$ 187.7$ \\
\hline
\end{tabular}

\section{Table 1. IDEA funding for FY 2015}

Even though West Virginia became the $25^{\text {th }}$ state to mandate autism coverage (Charleston Gazette-mail, 2012), the coverage has a cap of $\$ 30,000$ for the first three from the date treatment commences. After that, families receive $\$ 2,000$ monthly till the child reaches the age of 18. And this can be applied only toward evidence-based therapies like Applied Behavior Analysis (ABA). However, depending on the severity of the diagnosis, annual costs could be upwards of $\$ 50,000$ (autismspeaks.org, 2011). With limited resources, and lack of access to education, knowledge, medical help and lack of certified teachers, many parents in West Virginia aren't able to access the necessary services or have to pay out-of-pocket to support their children diagnosed with autism.

The purpose of this project is to showcase these stories on a publicly accessible medium to create empathy, interest, and also act as a source of information about the autism educators in the greater Morgantown, West Virginia area for those involved professionally and personally within the autism community. Media attention at large, in West Virginia and nationally, is often placed on new behavioral or teaching techniques, new research and medical updates regarding autism. However, not much is focused on the teacher's perspective, how they emotionally and 
professionally manage to teach children with autism given the limited resources available in a state like West Virginia.

This project will attempt to contribute to the existing media, explore autism teachers in Morgantown, W.Va., and add to the resources that families affected by autism in the area can use to better understand the available local support via teachers and educators. The project explores what it means to be an autism educator through their perspective. The multimedia project employed structured interviews that were audio-recorded and have been compiled with photo stills that captured their regular day at work. The structured interview consisted of five core questions and other follow-up questions prompted during the interview. The sound bites collected during the interview were edited alongside the stills captured. This multimedia pieces are available on an external website and is accompanied by short bios.

The project includes interviews from four autism educators with vastly different backgrounds such as: public school education, private education, behavioral clinic and the perspective of a student in-training to become an autism educator. Website users and viewers are able to read as well as visually see the autism educators' personal gratification and professionals struggles they encounter as special needs teacher to unique children with special needs. The ultimate goal of the project has been to create empathy and better public understanding of the consequent impact these educators have on their special-needs students and their families in Morgantown, W.Va. and beyond. 


\section{Professional and Educational Qualifications}

The experiences I have gained during my coursework for my bachelor's in broadcast journalism from West Virginia University, and a master of science in journalism from the same university has given me a solid educational background in journalism and the necessary understanding of journalistic ethics to fulfill the audiovisual portion and has equipped me with other technical skill sets required to achieve this professional project.

In addition to my educational background, I worked as a news and video productions graduate assistant at WVU Medicine' marketing and communications department. My duties for this position included: interviewing, editing, researching, shooting and producing multimedia video health reports that are uploaded to WVU Medicine's website and their social media platforms. Furthermore, after graduating in 2013 with a bachelor of science in broadcast journalism, I worked at bi-weekly English magazine, Y Magazine in Muscat, Oman for a period of eight months. During my time there, I worked as a reporter covering wide range of news stories, including pieces on news, health and lifestyle.

I believe my previous experiences as a student journalist, producer and a real-time reporter for a magazine, provided me with the necessary qualifications required to achieve the final audiovisual project.

\section{Project Description}

The project was carried out in Morgantown, West Virginia. The autism educators working in private organizations as well as in a school setting were interviewed for the project. 
The organizations include: Play Works Child Development Centre, Intensive Autism Service Delivery Clinic under West Virginia University's Center for Excellence in Disabilities, and an educator from the Monongalia County Schools system.

The interviews were audio recorded and the interviewees were asked a set of five core questions and other follow-up questions on their professional and personal experiences of having worked with autistic kids and within the autism community.

On the external website, the edited versions of the audio-recorded interviews are complemented with documentary-style photographs that were taken by me during each of the interviewee's teaching session.

By exploring an aspect of Autism and its prevalence in today's society, the project covers a facet of health journalism and is portrayed as a visual journalism project on the external website. It incorporates audio and photography slideshow along with short bios. For the external website, I used a template on the WordPress.com site to create and present the project on autism teachers.

\section{Project Timeline}

To accomplish the project in a timely manner, I have reserved the entire spring, summer and fall semester in 2016 to research, write, interview, and assemble the final project together. I have spent the first half of spring 2016 semester to gather research on this particular topic, and discovered gaps created because of under reporting on the plight of autism educators by the media that could be filled through the completion of this project on Autism and its educators. 
For the project, I interviewed four autism educators from varying backgrounds from around the Morgantown, West Virginia area. Keeping in mind the time required to reach these professional individuals and set an agreeable time to conduct the interview and capture photos, the complete interviewing process took about three months in total. This included at least two appointments with each of the interviewees.

After collecting all of the interview material, to transcribe audio-recorded interviews, writing the scripts, and choosing the appropriate photos for each interviewee took up to twothree months. The project also included creating a website on WordPress.com and using a survey and collecting results on the website functionality.

\section{Project Dissemination}

The project will be published and disseminated through a customized WordPress website. The website itself can be embedded and shared to intended audience through the unique link provided. The WordPress blog consists of separate pages for each interviewee. The external website is free and open to the public. People looking for information on autism educators could find the site through any search engine through regular keyword searches. The written aspect of the project will contain the introduction, project timeline, research questions, and the pertinent literature review of past research on the topic.

\section{Intended Audience}

The project - 'Autism Educators in Morgantown, W.Va., A Multimedia Story Of Their Trials and Triumphs,' is intended for a wide variety of audience within the autism community in 
Morgantown and surrounding areas that includes: parents of children and adults with autism, family and loved ones, and also, other autism educators looking for support and morale can find this project relevant, relatable, and useful. Additionally, organizations like Autism Speaks and many other local not-for-profit groups looking to educate and spread awareness on all facets of autism can use this project to talk about the differences and similarities each of the educators display in this project on their professional websites.

\section{Potential Publication Sources}

The project's intended audience is mainly those who are affected and directly involved in the autism community. This audiovisual project explores a human aspect of ASD. Therefore, it can be categorized as health-related news. This will mean that it could be published by health journalism outlets like the Association of Healthcare Journalists (ACHJ) and even presented at their annual conference.

Various not-for profit autism awareness groups like autismspeaks.org can also publish the multimedia story on their website as a parent resource on what different types of autism educators are out there. The multimedia elements can be independently listed under resources available in West Virginia. This will likely help parents of recently diagnosed children as they search for teacher resources in the Morgantown and surrounding area. These multimedia pieces on various autism educators and their perspectives can also increase awareness on a very different, yet vital part of dealing with ASD.

Autism educator-centered organizations like the autismeducators.com can also list these multimedia pieces under parent/teacher resources for new teachers looking for guidance as they 
begin their professional careers serving the autism community. It could be an educational tool on the realistic expectations they can form based on the audiovisual pieces.

The project could hopefully also gain attention from the mainstream news organizations due to its relevant human emotional aspect of the story; there could be a possibility of greater public understanding regarding the necessary legislative changes required to meet the demands of special needs educators and create a sense of empathy for those within the autism community.

\section{Research Statement}

The number of children being diagnosed with autism in West Virginia is growing but the research is yet to find the root cause of this neurological disorder. Parents within the autism community are constantly looking for more help and more answers as they try to deal with the few known facts of autism and they usually look to special educators for help and moral support as they help autistic children transition into daily like. This multimedia project on four different autism educators from various professional backgrounds in the Morgantown area showcased on an external website, hopes to contribute to the existing media on autism and act as tool of awareness about the educator community as they describe their professional and personal experiences. 


\section{Methodology}

During my initial research for the project, to the best of my knowledge, I found that in Morgantown, while there were plenty of media reports on the families affected by autism, professionals reporting on new research and information, there wasn't much covered on the autism educators and their perspective and journey within the autism community, both professionally and personally, in the autism community. They are often the people that parents of those affected by autism turn to for answers, moral support and possible progress.

At first, I decided to make an audiovisual project to fill the gap in the media coverage on autism educators. However, the topic turned out to be too broad and I felt that I couldn't cover all the important points within the available time to complete it. So, I decided to narrow down on the topic and focus on the profiles of autism educators from various professional backgrounds in Morgantown, W.Va. This switch in the project made it more relevant to the local community and the intended audience was now reduced to those specifically inside the autism community like the parents, teachers and medical professionals.

Due to lack of federal funding, resources, and lack of research, autism educators in Morgantown and other rural areas of West Virginia struggle with being able to provide the best intervention and education for the growing number of autistic children. In a disorder where early intervention makes all the difference, parents often struggle with the high investment of time and money required for progress. However, even autism educators rely heavily on the parents to achieve the best potential outcome for autistic children. This project highlights the perspective of four different autism educators from the Morgantown community: an occupational therapist from PlayWorks, Behavioral Psychologist and a student-in-training from 
the WVU Center for Excellence in Disabilities and an autism mentor from the Monongalia County Public Schools.

For the project, I employed audio-recorded personal interviews and documentary-style photography to show case what a regular day looks like for an autism educator. My interviews consisted of five core questions and follow-up questions on what brought them into the autism community, personal experiences in the years so far and future possibilities. On a separate visit to all three locations, I took photos during regular teaching sessions after receiving consent from the children's guardians.

The professional project includes strong multimedia storytelling by incorporating the audio recordings with documentary-style still photography of the interviewees and other visual elements along with short bios. The external website was constructed using a WordPress template and is publicly available for anybody interested in learning more about various educators who work with kids with autism.

The multimedia project is intended mainly for those within the autism community. Visitors to the website can learn about the educators profiled in this project by listening to multimedia projects. They can also read small bios with the educator's qualifications, journey into the autism community and their hopes for the future for those affected by autism. Visitors can also comment on the website, share it on social media, suggest improvements and offer personal opinions.

\section{Interview Questions}

Below are the five core interview questions I asked all the autism educators who participated in this project: 
1. What motivated you to become a special needs educator for children with autism spectrum disorder?

2. What does your day as an autism educator look like?

3. How do you think your job differs from that of other regular teachers for students of the same age group?

4. What do you think is the hardest part about being an educator for a child with ASD? Why?

5. What is the most positive aspect of your job? Why?

\section{External Website}

The external website is located at www.autisminmorgantown.wordpress.com. It was created using free version of a WordPress.com template. The main page consists of six categories on the menu column: Home, Dr. Susannah Poe, Miranda Smalley, Michael Lentz, Regina Chisler, and Resources. Each of the tab contains content relating to its heading. For example, in the 'Home' tab, there is a description about ASD and the project. It also consists external links to sources acknowledged in the description. In the tab next to 'Home,' in 'Dr. Susannah Poe,' there is a Soundslides project uploaded to Vimeo, a video-sharing website, embedded in the page containing audio and photos from the interview. The project is accompanied by a feature image of the person interviewed along with a short bio for introduction and background information on their professional qualifications that made them eligible to be interviewed for the project. 
The website and each of the pages have tags or metadata with keywords so that they are search engine optimized (SEO) for best search results on online information websites like Google, Yahoo, Bing etc.

The website is easy to maneuver and is mainly intended to serve as an addition to the existing media content on ASD. Additionally, the website is also intended to serve as different facet of information on autism that's both useful and relatable for teachers, researchers, families of autistic individuals and anyone else looking to learn more about education for autistic individuals in Morgantown, W.Va.

\section{Survey}

In order to find out whether the project as an external website contained useful and relevant information, easy to navigate, credible, visually appealing and interactive, a short and quick survey was the best method to gather some feedback. Using SurveyMonkey.com, an online survey builder, I put together a short eight-question survey (appendix 2) and shared it via email, social media and additionally requested the survey to be shared by the respondents. The survey included six close-ended questions, one question asking respondents to rank the projects

from most to least favorite or useful, and one open-ended question asking comments and suggestions to improve the website.

The close-ended questions was listed as a means to find out answers regarding website functionality. As I have chosen an external website to showcase my project, it was important to make sure that the website was not only visually appealing, but easy to navigate and share the 
information if necessary. Additionally, making the content available on the website credible and trust-worthy was imperative.

\section{Survey Results}

After the surveys were returned, I analyzed the collective data and summary to verify their significance for my research. The survey had a total of eight respondents. While I had to eliminate some of the answers due to misinterpretation of the question, majority of the answers in all of the surveys helped me get a better understanding of my website's current usefulness, reliability, appeal and efficiency.

In the first question, I asked if the website was easy to navigate. While five of the respondents found the website 'extremely easy' to maneuver, three of them found it 'very easy.' In the second question, I wanted to find out if my respondents interacted with autistic individuals. This was mostly important, as the intended audience for this project is teachers, researchers and families of autistic individuals. However, since the survey was shared via social media and email and mostly aimed at professionals whose work revolves around children who need special education, four of the respondents sometimes interacted with autistic individuals and four listed not at all.

In the third question, I asked the respondents to rank the audiovisual project one to four with their favorite ranked one and least favorite ranked four. However, through the results, it was immediately clear to me that three of the respondents misinterpreted the question and did not completely answer the question. Despite missing some answers, with the results available, Dr. Susannah Poe's story ranked highest and Regina Chisler's story, the least. 
Question four asked if the website had useful information. While five of the respondents found it quite informational, three found it moderate helpful. Question five asked about the visual appeal of the website. Seven of them responded that they found it very or extremely appealing. In question six, seven of the respondents said they found the information on the website very credible. As the project is located online, the means of finding the website is through keyword searches or through recommendation. In question seven, seven of the respondents answered that they would recommend the website to others.

The last question in the survey was an open-ended question asking for suggestions or comments to improve the website's usefulness and functionality. Only five of the respondents answered it while three skipped it. Three of the comments were very useful. Two of them suggested that instead of short bios on each page, they would have liked to see more background information on the teachers interviewed. Another comment pointed out that including closed captions on the audiovisual projects would benefit those who have hearing impairment.

\section{Literature Review}

There is a plethora of news articles and media coverage through various platforms on autism spectrum disorder spanning various topics like controversial scientific causes such as: vaccination and autism link that has since been disproved, emotional journeys experienced by autistic children, adults and their families; new educational strategies that can be used by teachers and mentors, in public and private schools etc. On the contrary, there is a clear lack of insight when it comes to exploring the personal journeys experienced by those very 
professionals who work long and hard hours with children and adults with autism and strive to create a better quality of life for them.

Autism educators have a various qualifications that all together and separately, help in establishing a feasible lifestyle for many. These educators could be behavioral specialists, special education mentors at public schools, certified hearing and speech therapists, occupations

therapists, physical therapists and more. I intend to present the project through multimedia storytelling using personal structured interviews, still photography, and text. Often, with sensitive topics such as ASD, the health and science reporting and coverage needs to be approached in a different way. Additionally, adding a visual documentation method through photography, the project will need to adhere to certain guidelines in order to respect the emotional and vulnerable experienced of the interviewees involved. To deepen my understanding for the approach, I have divided the literature review into the following categories: previous media coverage on ASD, effects of multimedia storytelling, and health and science reporting

\section{Previous media coverage on Autism Spectrum Disorder}

As April encroaches, media reports are filled with news pieces on ASD to bring the developmental disorder to light in time for Autism Awareness Month. The media coverage is wide and covers anything from new research, to updated statistics, and the struggles and joy faced by children or adults on the spectrum, and its consequential affects on family and friends. For example, Huffington Post posted an article (2016) titled, ‘Autism's Big Elephant in the Room,' authored by Holly Robinson Peete, an advocate and mother to a teen with ASD. The 
New York Times, on Autism Awareness Day, had a mother (2015) recount the struggles of parenting her four-year-old autistic son on their blog, 'Motherlode.' Forbes went ahead and did an article with generic information update called (2016) on '7 Things You Need To Learn About Autism.' Major broadcasting giants like CNN and FOX News included news stories in the form of profile pieces, CDC update on prevalence of ASD and community awareness programs across the country for the month of April.

As a matter of fact, selective media attention to certain developing research on ASD has actually caused more harm than good. In 1998, physician and researcher, Andrew Wakefield research on the possible link between measles, mumps, and rubella (MMR) and the autism (Wakefield et al., 1998) was published by the British Medical Journal, The Lancet (Holton et al., 2012). This caused a frenzy among the society, news media and researchers alike. While a lot of scientists and other physicians refuted the link, the damage had already been made. There was a deep distrust in the contents of the vaccine (Petts \& Niemeyer, 2004) and this led to decrease in the MMR uptake among society. This in turn resulted in the resurgence of MMR in the United Kingdom and elsewhere.

While research, development, and feature stories on children on the spectrum, their consequential struggles, even news on research regarding early intervention tactics, and teacher resources are given regular media attention. But, the teachers themselves go under appreciated for the monumental impact they have in these children's lives.

After scanning the Internet, other than a few personal bogs and YouTube videos by autism teachers, there was not much content dedicated to them. Especially when physicians, psychologists, and other researchers stress on the important of early intervention for better 
outcomes for children and adults with ASD, the importance of the role of an autism teacher in enhancing the overall quality of life does not get enough attention from the media.

\section{Effects of Multimedia Storytelling}

I choose to take the multimedia storytelling approach because audio and photos, I'll be able to better communicate what the reality of a regular workday for an educator who deals with children with autism looks like, viewers and listeners can truly then grasp the message trying to be conveyed.

With the extensive dependency on the Internet for all things news and information in the current, fast-paced world, using multiple sensory, and cognitive effects (Sundar, 2000) has become the norm practiced by many news agencies to retain reader attention. Deuze (2004) says that multimedia can be defined in two ways: first, it can be seen as a presentation of news story package with two or more media formats such as, audio, text, photography (moving and still), video, graphics, animations etc. Secondly, as a presentations of the news story package through multiple media platforms such as, T.V., radio, newspapers, magazine, online websites, e-mail, SMS, MMS etc. However, in today's smartphone usage, news platforms could be extended to Facebook, Twitter, Instagram, Snapchat, YouTube, Periscope, Reddit, Tumblr, and many more such websites.

The popularity of multimedia news storytelling picked up mainly because it was able to translate the story in more forms than text, audio, photos or video alone could communicate. According to Sundar (2000), researchers have stated that the concept of redundancy is the 
reason why viewers are able to better ingest the information when presented through multiple rather than single modality.

In order to better understand the psychological process and perception of news through multimedia presented on websites, Sundar performed a focus study through a survey assessment to find out. He collected surveys filled out by sixty undergraduate students to calculate the results. One of the results of the study included that picture, when presented along with audio, had a positive effect on the participants and led to better memory recall.

Unlike using text alone, multimedia can enlighten viewers and listeners through the rich audio, photo stills or video along with a brief text. And this can deepen the message, and also clarify it. Multimedia storytelling can reduce the time required to read it and instead, one can just experience the story. One of the best examples for multimedia storytelling, and an inspiration for this project, is the New York Times project, 'One in 8 Million.' The multimedia project involved documentary style photography presented in black and white with audio underneath. It aims to capture the unique individuals living in New York City and their regular, yet unique story. So far, the project has covered fifty-two such profiles.

Another good example is an in-depth interactive investigative story series that National Public radio (NPR) put together on the cotton industry in a series called, 'Planet Money Makes a T-Shirt.' The project included graphics, video, and detailed text split-up under several titles alongside the step-by-step process involved in cotton production in the U.S to make a t-shirt. Even though NPR is primarily a radio network, they have introduced this interactive multimedia storytelling platform to reign in more viewers, expand the storytelling experience, and to spread the appeal. 


\section{Health and Science Reporting}

Today, the Internet has become the go-to medium for health-related information among the public. According to a survey conducted in 2012, by the Pew Research Center, $72 \%$ of the adult American population admitted to looking for health information online in that year alone. The survey also revealed that among the most commonly researched topics, were diseases or conditions, treatments or procedures, or doctors or other health professionals. With growing numbers of users looking online for health-related issues, Secko (2009) says that the medium of Internet, for science and health journalism, can be seen as a 'hybrid-channel,' where one can disseminate news to a mass-audience through multimedia platforms but retains the traditional values of interpersonal communication. Secko elaborates, "enthusiasm has been generated by theorizing over the potential for online interactivity to help people internalize health/scientific messages and examine them with greater scrutiny."

However, with science or health-related reporting, too often, studies are exaggerated or lack balance in reporting because of the overwhelming complexity of the issues involved. To mitigate that, health or science reporters could cool to websites like healthnewsreview.org. The website has a strong editorial team with years of health-care journalism experience. These editors take science stories and critique them based on a five-star rating. This could a good way to keep the scientific content being reported in check.

Some of the finest examples of multimedia science and health reporting can be seen on NPR's global health blog, 'Goats and Soda.' One of their noted recent works is 'Life After Death,' (NPR, 2015) a multimedia news package with photography and audio covering the 
Ebola crisis in the village of Barkedu in Liberia. The project aimed to create empathy through audiovisual representation of the crisis that resulted in thousands of deaths.

One of the reasons these multimedia stories have a strong reaction from the readers is because they employ audio clips in company of documentary-style photo stills and rich text. Audio clips are great at conveying empathy and humanizing the story with a place and personal connections (Rosa, 2009).

\section{Media Theories}

My professional project focuses on personal and professional experiences autism educators face on a daily basis. They work to serve the community they live in and the parents of children with autism look to them and others in the field for answers and support. Media coverage on topics like autism should be done often and approached from all angles as the stories directly stand to act as a tool of awareness or creates empathy for the readers. I believe civic journalism and social responsibility theory resonate and accurately support the research statement for this project.

\section{Civic Journalism}

In their research to see the relation between civic journalism and the Freedom of Information Act, James Simon and David Allen Sapp (Simon \& Sapp, 2006) described what they believed civic journalism stood for: 
Civic journalism positions the reporter's role beyond objectively providing information and facts in a news story; instead, the role is seen as having the potential to affect public life and empower a community.

As journalists, I believe that, at times, we hold the responsibility to step out of the traditional journalistic code of being only a neutral observer, and instead, navigate discussions to bring more light to topics that have been ignored by the news media in their coverage.

In terms of health and science reporting, by applying values of civic journalism, news could be seen as playing a significant role in the process of informing and defining health and social issues, and legitimizing probable solutions for them (Hodgetts, 2012).

For example, the Akron Beacon Journal (1998) published a yearlong series on race relations, 'A Question of Color,' aimed to raise awareness on the socioeconomic disparities between blacks and whites in the Akron, Ohio area. The project also aimed to educate community members and bring them together in appreciating all cultures and their acknowledging their problems.

In civic journalism, unlike public or citizen journalism, the informers of news are still trained, professional journalists who uphold the basic ethics and codes of traditional journalism like unbiased and balanced reporting. However, they add an element of community awareness on certain under reported elements of society that sometimes mainstream media shies away from as they may not deem newsworthy.

\section{Social Responsibility Theory}

As McQuail (2005) points out, the Internet allows its users a plethora of information regarding various topics. However, a journalist has an obligation to report and produce stories 
that are truthful, objective, relevant and accurate even if the medium of distribution is online on a blog site.

Internet is the one medium where it affords its users the ability to share, tweet, like or comment on the content just through a single click (Singer, 2006). However, for journalists on the Internet, the social responsibility theory has never been more applicable. On a medium where users hold complete autonomy on what content is disseminated, content available on a sensitive topic like autism and information that largely affects the autism community should be crafted and presented responsibly.

Loved ones and researchers scanning the Internet for any useful information on autism belong to a vulnerable community. It's imminent that journalists use irrefutable form of fact checking and adequate background information and research while creating health-related content for free public access online.

\section{Conclusion}

\section{Limitations}

Like any project, the multimedia project on autism educators in Morgantown, W.Va. had its own set of hurdles. Firstly, limited amount of time to complete the project made the scope of the project quite narrow and I had to forego many wide-reaching ideas in regards to the project to be able to finish the project on time. From concept to completion of the project, I was able to dedicate only the Spring 2016, Summer 2016 semester and Fall 2016 semester. I had to share my responsibility of finishing the project with a part-time graduate assistantship, an online class 
and an independent study on sensor journalism. In addition to that, In Sept. 2016, I accepted a full-time position outside of Morgantown.

Due to the lack of time and other commitments towards my degree, I had to restrict my location to only Morgantown, W.Va. Without a reliable mode of transport and academic commitments, I could work with teachers working only in Monongalia County. Besides, a topic like autism is often a vulnerable topic for all involved including the parents, teachers and other professionals. This project required me to interview educators in the community who had disclosed the names and personal information of their students - mostly minors, and their personal and professional opinions and experiences within the autism community.

Additionally, as my project required documentary-style photography, I needed complete access into the complicated lives of young autistic individuals between the ages three to twentyone. In order to conduct this project ethically, I had to obtain consent forms from all those who were either interviewed or photographed during the course of the project. This required some amount of persuasion and explanation of the project's intention and it was time consuming.

As far as editing software for the project is concerned, I had to buy the Soundslides software to create the audiovisual projects for $\$ 40$. While not too expensive, the upgraded version of the software, available for $\$ 70$, would have allowed me to include closed captions and create projects with higher resolution and embed them directly onto the website instead of uploading them to Vimeo as a medium to share. Additionally, with an upgraded version of WordPress.com template, I could have installed pre-made SEO and Google Analytics plugins that would have collected data from all visitors to see the incoming traffic on the website to determine data-driven results. 


\section{Future Research}

While there are a lot of studies being done on ASD and its causes and effects on children and adults, there are a lot factors still unknown about the developmental disorder. As the number of autism cases is on the rise with increasing population, the socio-economics of funding for research, special education, and establishing policies that will address the problem are still to be discussed at length. My project mainly focused on the issues teachers face while dealing and supporting autistic children. In the future, a similar project that follows-up with the same children functioning as adults in the real world could be a good project.

In relation to my current project, If I wasn't limited by time and access, I would have liked to interview autism educators from different parts of the state of West Virginia, especially the rural counties in southern West Virginia as this would have exposed the extent of the problems autism educators and parents could be experiencing and bring to light some of the issues caused by lack of resources and funding in a non-university environment. 


\section{Sources}

Centers for Disease Control and Prevention. (2016, July 11). Retrieved from http://www.cdc.gov/ncbddd/autism/data.html

Deuze, M. (2004). What is multimedia journalism? Journalism Studies, 5(2), 139-152.

Early Signs of Autism. (n.d.). Retrieved from http://www.nationalautismcenter.org/autism/early-signs/

Eyre, E. (2012, February 13). Parents push autism bill 'clean-up' Retrieved from http://www.wvgazettemail.com/News/201202130219

Facts about Autism. (2015). Retrieved from http://www.nationalautismcenter.org/autism/

Holton, A., Weberling, B., Clarke, C. E., \& Smith, M. J. (2012). The blame frame: Media attribution of culpability about the MMR-autism vaccination scare. Health Communication, 27(7), 690-701. doi:10.1080/10410236.2011.633158

IDEA Funding Gap. (2015, February 2). Retrieved from https://www.nea.org/assets/docs/IDEA-Funding-Gap-FY 2015-with-State-Table.pdf

Intensive Autism Service Delivery Clinic. (2016). Retrieved from http://clinics.cedwvu.org/autism/

Lord C, Risi S, DiLavore PS, Shulman C, Thurm A, Pickles A. (2006). Autism From 2 to 9 Years of Age. Arch Gen Psychiatry.2006;63(6):694-701. doi:10.1001/archpsyc.63.6.694.

Planet Money Makes A T-Shirt. (2013). Retrieved from http;//apps.npr.org/tshirt

Prochnow, A. (2014). An analysis of autism through media representation. ETC: A Review of General Semantics, 71(2), 133.

Raffin, C., Dr. (2001). A multidisciplinary approach to working with autistic children. Educational Ad Child Psychology. doi:file:///Users/Shishira/Downloads/Approccio_multidisciplinare (2).pdf

Secko, D. M. (2009). The unfinished science story: Reflections on journalist-audience interactions in the online environment. Journal of Media Practice, 10(2), 259-266. doi:10.1386/jmpr.10.2-3.259_3

Secko, D. M., \& Smith, W. A. (2010). Health journalism: Fracturing concerns and building reflective capacity with a deliberative lens. Canadian Journal of Communication, 35(2), 265-274. Retrieved from http://search.proquest.com/docview/807508834?accountid=2837 
Shah, A. (2009, December 6). Learn to Love Multimedia with KQED's Craig Rosa. Retrieved from http://www.centerforhealthjournalism.org/blogs/learn-love-multimedia-kqedscraig-rosa

Sundar, S. S. (2000). Multimedia effects on processing and perception of online news: A study of picture, audio, and video downloads. Journalism and Mass Communication Quarterly, 77(3), 480-499. Retrieved from http://search.proquest.com/docview/216926923?accountid=2837

Teaching Students with Autism - Guide for Educators. (2002-2015). Retrieved from http://www.nea.org/home/18459.htm

West Virginia Becomes 25th State To Enact Autism Reform Legislation. (2011, April 01). Retrieved from https://www.autismspeaks.org/advocacy/advocacy-news/west-virginiabecomes-25th-state-enact-autism-reform-legislation

Willey, S. (1998). Civic journalism in practice: Case studies in the art of listening. Newspaper Research Journal, 19(1), 16.

Workman, M. (April 2, 2012, Monday ). More autistic children calls for more educated teachers, researchers say. Charleston Gazette (West Virginia), Retrieved from http://www.lexisnexis.com/hottopics/lnacademic

1-in-8 Million - The New York Times - Breaking News, World (n.d,). Retrieved from http://www.nytimes.com/packages/html/nyregion/1-in-8-million/index.html 


\section{Appendices}

\section{Appendix 1. Media Consent Form}

Without expectation of compensation or other remuneration, now or in the future, I hereby give my consent to Shishira Nanjangud Sreenivas to use my image and likeness and/or any interview statements from me in its publications, advertising or other media activities (including the Internet). This consent includes, but is not limited to:

(a) Permission to interview, film, photograph, tape, or otherwise make a video reproduction of me and/or record my voice.

(b) Permission to use my name; and

(c) Permission to use quotes from the interview(s) (or excerpts of such quotes), the film, photograph(s), tape(s) or reproduction(s) of me, and/or recording of my voice, in part or in whole, in its publications, in newspapers, magazines and other print media, on television, radio and electronic media (including the Internet), in theatrical media and/or in mailings for educational and awareness.

This consent is given in perpetuity, and does not require prior approval by me.

Name:

Signature (guardian):

Address:

Phone:

Date:

The below signed parent or legal guardian of the above-named minor child hereby consents to and gives permission to the above on behalf of such minor child.

Signature of Parent or Legal Guardian: Print Name:

The following is required if the consent form has to be read to the parent/legal guardian: I certify that I have read this consent form in full to the parent/legal guardian whose signature appears above 


\section{Appendix 2. Survey}

This survey was available online at https://www.surveymonkey.com/r/5TRJDMT

Q1. Does the website appear easy to navigate?

○ Extremely Easy

o Very Easy

○ Somewhat Easy

○ Not so easy

○ Not at all easy

Q2. How often do you interact with an individual with Autism Spectrum Disorder (ASD)?

- Extremely often

- Very often

- Sometimes

- Not very often

○ Not at all

Q3. Rank the content you found most useful or relevant

- Miranda Smalley

- Michael Lentz

- Dr. Susannah Poe

- Regina Chisler

Q4. Do you find the website informational?

○ A great deal

○ A lot

○ A moderate amount

- A little

○ Not at all

Q5. How visually appealing is the website?

- Extremely appealing

$\circ$ Very appealing

○ Somewhat appealing

- Not so appealing

○ Not at all appealing

Q6. How much do you trust the information on this website?

○ A great deal

○ A lot

- A moderate amount

- A little

○ Not at all 
Q7. How likely is it that you would recommend the website to your friend or colleague?

- Extremely likely

○ Very likely

- Somewhat likely

○ Not likely

$\circ$ Not at all

Q8. Do you have any other comments on how to improve the website? 
Appendix 3. Example of Adobe Audition Timeline

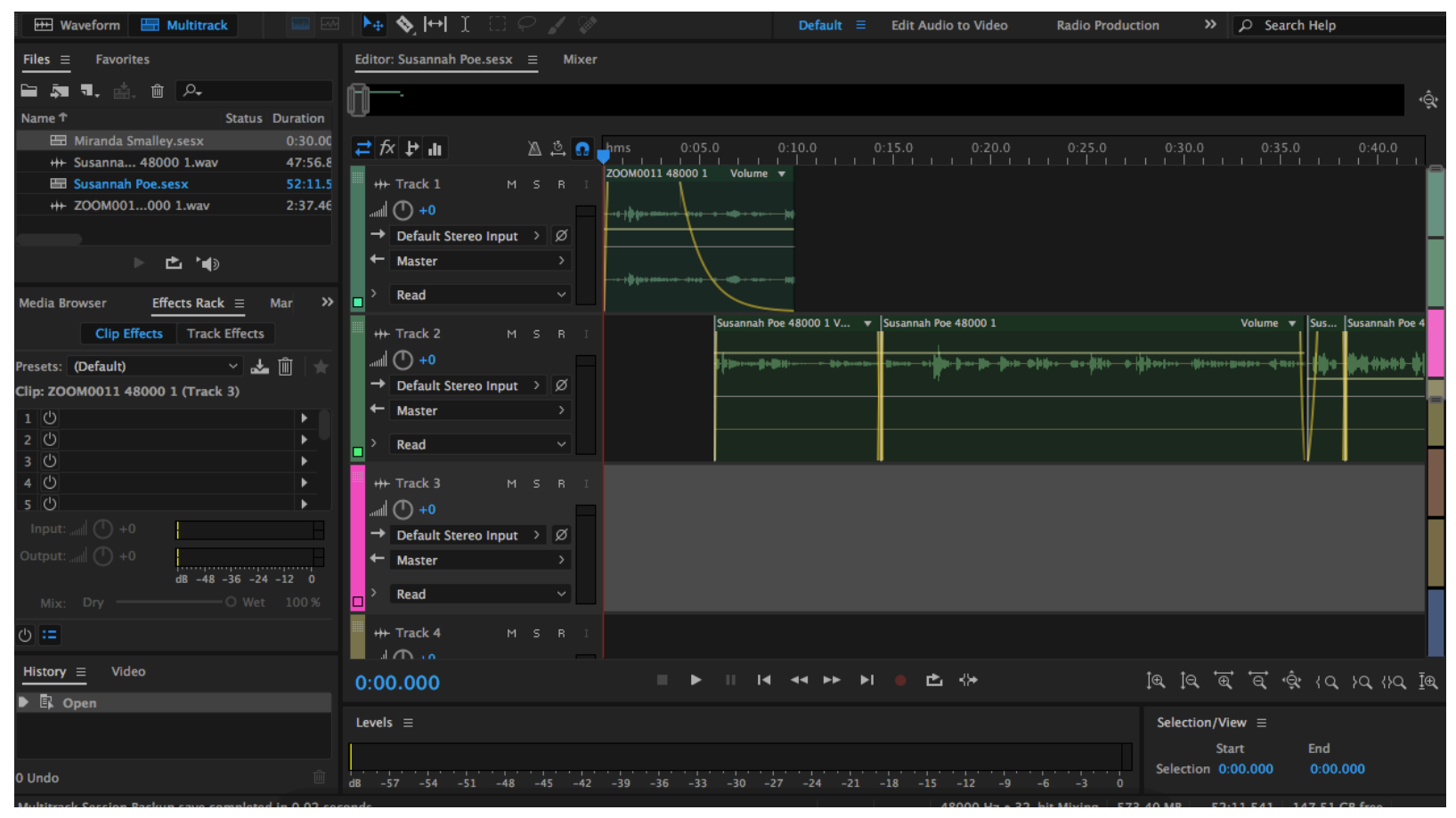




\section{Appendix 4. Example of Soundslides Timeline}

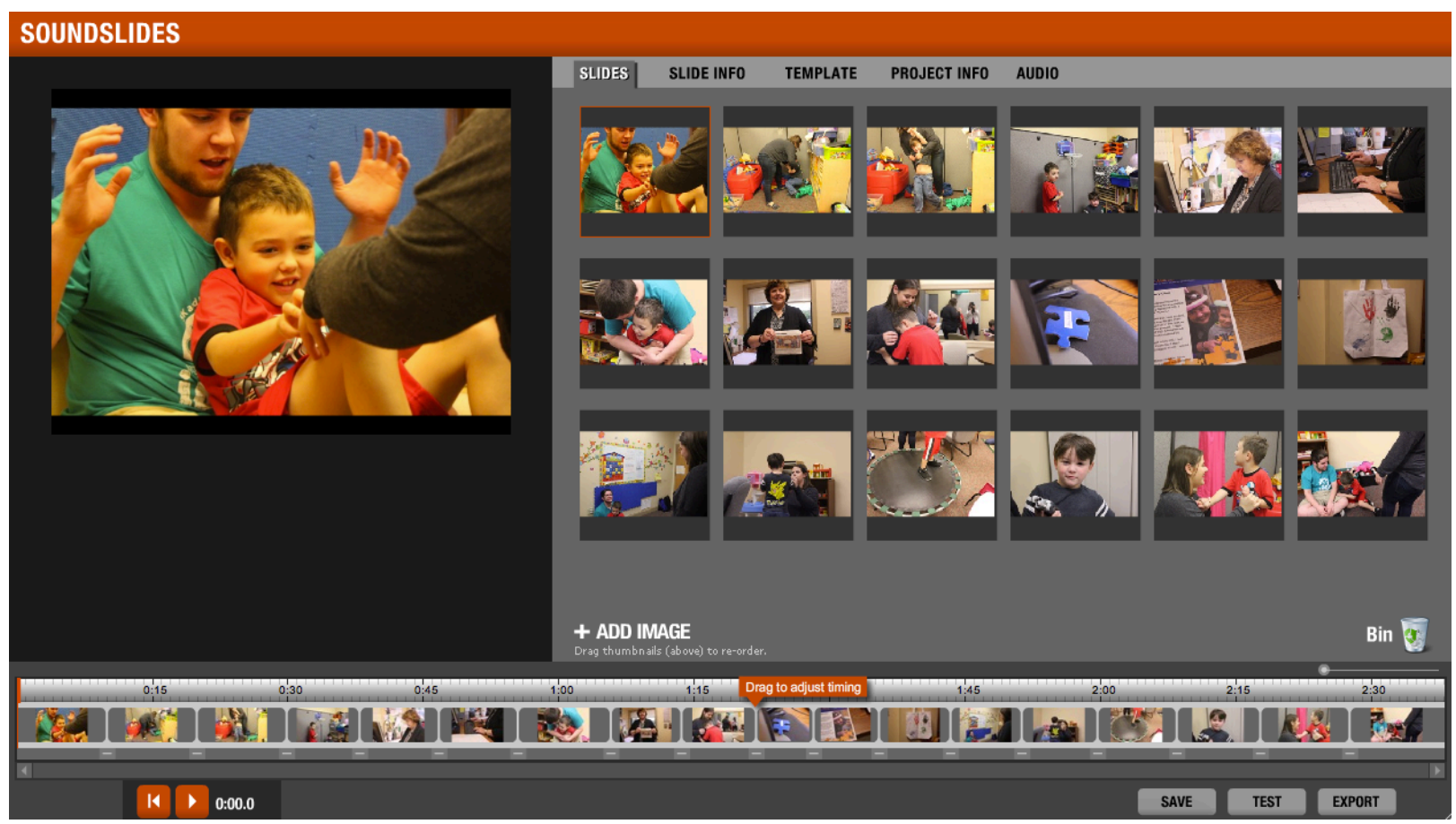




\section{Appendix 5. External Website}

The professional project titled 'Autism Educators in Morgantown, W.Va.: A Multimedia Story of Their Trials and Triumphs' is available as an external website:

https://autisminmorgantown.wordpress.com/

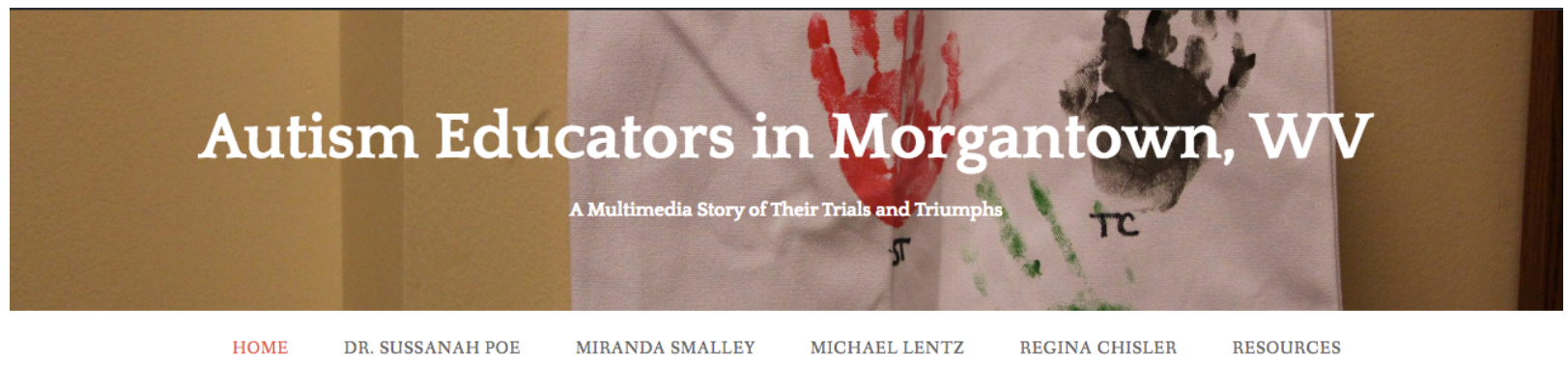

\section{About}

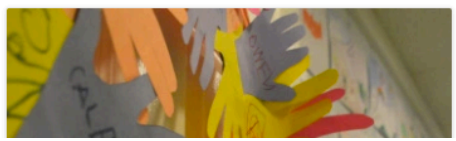

Autism Spectrum Disorder (ASD) is a neurodevelopmental disorder that is characterized by limited social interactions and social communicating and also by restricted and repetitive behavior. According to the Centers for Disease Control and Prevention (CDC), I in 68 children are diagnosed with ASD and it occurs in all racial, ethnic, and socioeconomic groups; and is 